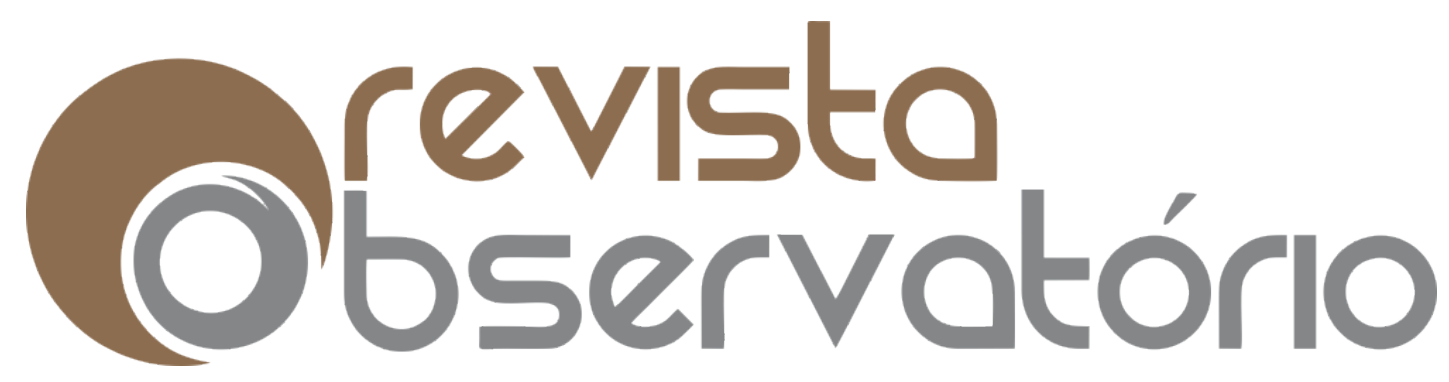

ISSN n² $2447-4266$

Vol. 5, n. 5, Agosto. 2019

DOI: http://dx.doi.org/10.20873/uft.2447-4266.2019v5n5p26

\title{
TECNOLOGIAS CIBERCULTURAIS E EDUCAÇÃO EMPREENDEDORA: Caminhos em construção
}

A Revista Observatório apresenta seu quinto número de 2019, com capa produzida pelo colega e artista Adriano Alves, trazendo dois dossiês especiais! Como parte do planejamento de 2019, a intensificação dos ajustes segue, o que tem resultado em uma maior visibilidade e citação da revista por parte dos leitores. Até a presente data, nossos 10 artigos mais citados geraram uma visibilidade grande, permitindo que a revista se destaque no meio acadêmico. Que tal conhece-los e citá-los? (SPINELLI; SANTOS, 2018; BUENO; REINO, 2018; ELHAJJ;; ESCUDERO, 2016; BERNARDO et al., 2015; CHIECHER et al., 2016; MOURA, 2017; VIANA; COSTA, 2017; MACHADO; COSTA; MORAES, 2018; NUNES; PORTO JUNIOR; MORAES, 2017; MELO, 2017; MIRANDA-PINTO; MONTEIRO; OSÓRIO, 2017). Esperamos que, até o fim de 2019 tenhamos esse número ampliado!

Iniciando nossos dossiês, o primeiro intitulado TECNOLOGIAS CIBERCULTURAIS, foi organizado pelos colegas Dra. Valdirene Cássia Silva, Dra. Irenides Teixeira, Dr. Edvaldo Couto e Dra. Liana Vidigal e tem o objetivo de socializar as pesquisas sobre o Jornalismo e suas aplicações. O segundo, intitulado EDUCAÇÃO EMPREENDEDORA, INOVAÇÃO E DESENVOLVIMENTO REGIONAL NO NORTE DO BRASIL, foi organizado pelo colega Dr. Kleber Abreu Sousa e tem como 


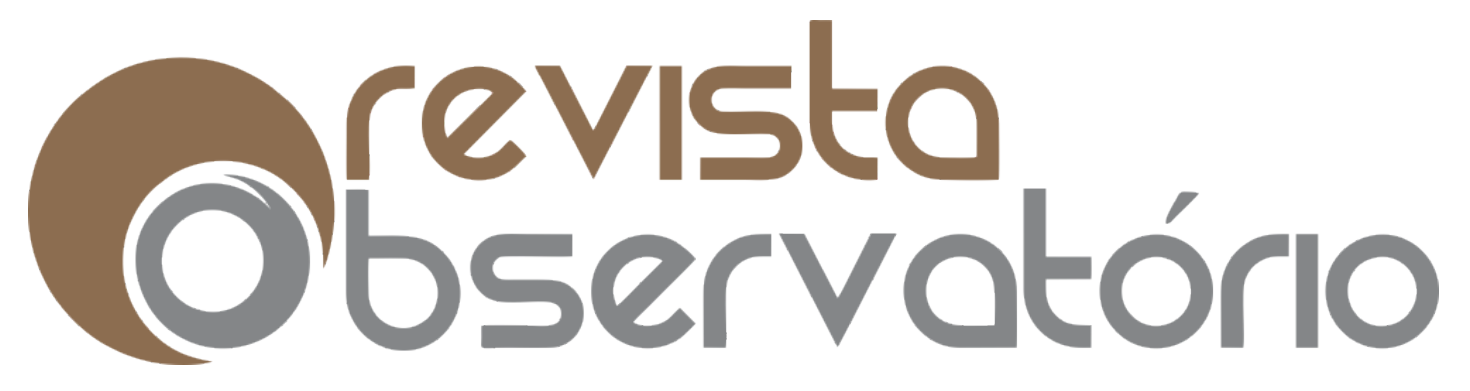

ISSN n² 2447-4266

Vol. 5, n. 5, Agosto. 2019

DOI: http://dx.doi.org/10.20873/uft.2447-4266.2019v5n5p26

foco trazer artigos que versem sobre a inovação e uma educação empreendedora em pesquisas no norte do Brasil .

Abrindo o dossiê TECNOLOGIAS CIBERCULTURAIS, o artigo intitulado ANTES DEL ALUVIÓN DIGITAL: los formadores de una escuela rurbana en la transición de la informática educativa os autores Edgardo Luis Carniglia e Cintia Betsabé Tamargo discutem a incorporação das tecnologias informáticas nos mundos rurais. Consequentemente, a seguir pretende-se responder, desde uma perspectiva de comunicação para o desenvolvimento, à pergunta sobre a posição dos integrantes da escolar urbana, em particular os docentes de um colégio secundário agrotécnico da pampa argentina, ante a informática educativa em uma conjuntura de política pública e outras estratégias com tendência à massificação do acesso a dispositivos digitais como o computador, as redes informáticas e a telefonia celular ou móvel.

No artigo intitulado ENTRE TWEETS: audiências, conexões e indexações de professores no twitter os autores Camila Lima Santana e Edvaldo Souza Couto apresentam alguns resultados de uma pesquisa qualitativa, descritiva e analítica já concluída em que o universo das práticas e estratégias de visibilidade, a partir das apropriações dos SRS, são as construídas por um grupo formado por dez professores no Twitter, aqui denominados, professores tuiteiros, considerando suas interações e ações docentes desenvolvidas a partir desta mediação. A pesquisa empírica foi realizada no período de março de 2013 a maio de 2014. O nosso objetivo aqui é discutir a natureza da audiência, associada à formação de redes sociais no Twitter e as formas de indexação utilizadas por esses docentes para potencializar a visibilidade nessas redes.

No artigo intitulado EXPOSIÇÃO DE SI NOS AMBIENTES DIGITAIS E OS DESAFIOS NA COORDENAÇÃO DAS REGRAS DE PRIVACIDADE os autores Rodrigo Nejm e José Carlos Ribeiro apresentam uma breve discussão sobre os atuais 


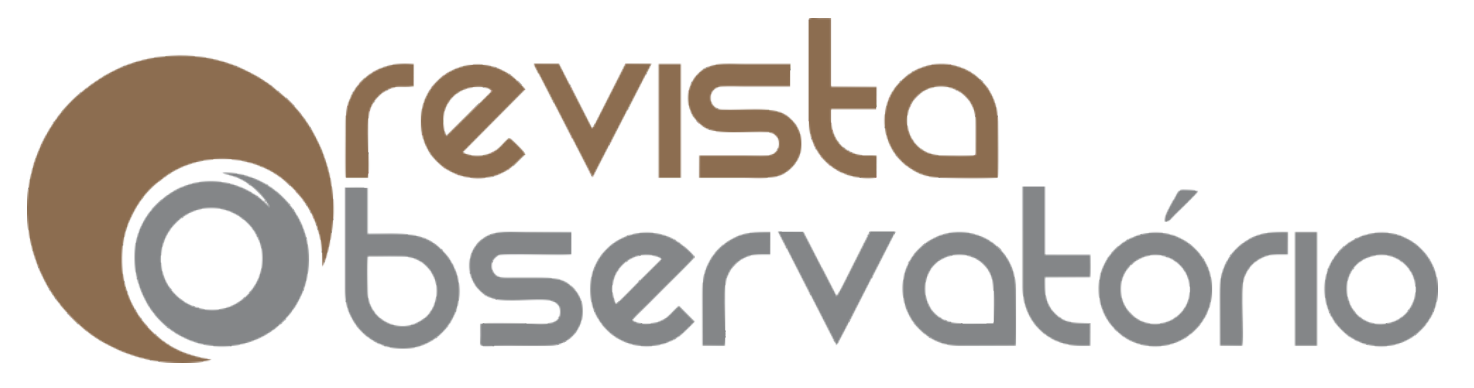

ISSN n² 2447-4266

Vol. 5, n. 5, Agosto. 2019

DOI: http://dx.doi.org/10.20873/uft.2447-4266.2019v5n5p26

desafios na coordenação dos limites da privacidade nos ambientes digitais, numa dimensão plural, com destaque à dimensão informacional, relativa ao fluxo de informações pessoais nas interações sociais efetuadas nos ambientes digitais, buscando enfatizar a noção de privacidade como aspecto não exclusivamente individual, mas eminentemente processual e relacional.

No artigo intitulado MÍDIA COMO CATALIZADORA DE DISCURSOS PÓSMODERNOS PARA OS JOVENS os autores José Carlos Miranda e Sonielson Luciano de Sousa abordam como a dinâmica contemporânea gera uma gama de jovens descontentes e frustrados, pois no panorama contemporâneo para que haja os vencedores, necessariamente deve-se fazer surgir a classe dos excluídos e inaptos. Assim, ter e aparentar originalidade custa caro, sendo, portanto, um privilégio que requer esforço ad eternun para que o jovem, mais à frente, não se depare com o fantasma da invisibilidade.

No artigo intitulado EDUCAR NO PRESENTE EFÊMERO PARA UM FUTURO INCERTO o autor José Lauro Martins desenvolve uma crítica à educação. A crítica de alguns autores quanto ao papel da escola na nova realidade educativa perante as possibilidades de interação e informação, chega a extremos. Há autores que consideram que a escola, diante dos avanços tecnológicos capazes de distribuir com eficiência a informação, perde a razão de existir (PERELMAN, 1992). Embora entenda que este seja um posicionamento reducionista e obtuso, uma vez que o papel da escola não é ou não pode ser apenas o de informar. No contexto deste artigo propomos um viés para o debate educacional para a educação no século XXI: por um lado as tecnologias digitais de comunicação e informação que abalam as estruturas centenárias da educação e por outro a autonomia que esta tecnologia possibilita contrasta com o modelo de escola e da educação oficial que temos.

No artigo intitulado O "EXTREMO" PARA PENSAR A CULTURA DAS JUVENTUDES CONTEMPORÂNEAS a autora Marluce Evangelista Carvalho 


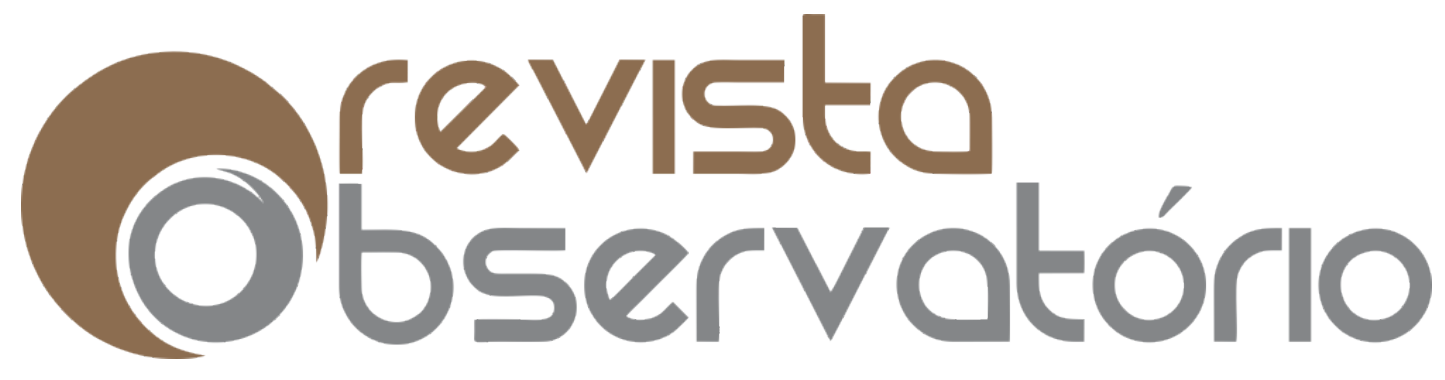

ISSN n० 2447-4266

Vol. 5, n. 5, Agosto. 2019

DOI: http://dx.doi.org/10.20873/uft.2447-4266.2019v5n5p26

Zacariotti desenvolve o conceito de eXtremo, de Massimo Canevacci, autor, cujas ideias inovadoras, e por que não dizer radicais, têm trazido boas contribuições para pesquisas sobre as juventudes, na interface comunicação/cultura/consumo na contemporaneidade. Trata-se também de uma perspectiva em plena discussão. Porque a temática juventude, destacada em inúmeras pesquisas, estudos, em incontáveis artigos, ensaios e livros que cada vez se proliferam mais, dada a sua crescente relevância, vem sendo abordada sob a perspectiva de vários campos do saber, gerando múltiplas possibilidades de percepção e teorização. Assim, estamos concordando com uma linha de pesquisadores, entre eles Canevacci, que caminham pelo terreno do múltiplo, do plural, envolvendo aspectos sócioculturais-econômicos-geográficos que falam não de um jovem, mas de jovens; não de uma juventude, mas de juventudes.

No artigo intitulado SOCIEDADE DO CONHECIMENTO: O uso das TIC por docentes e as novas articulações de saberes educacionais no sudeste do Pará os autores Francisco Evangelista, Karina Donizete Martins, Maria Fernanda Calil Angelini e Maria Josilene Fontinele Rocha verificam a adesão dos docentes e os entraves na utilização das TIC no processo ensino e aprendizagem numa IES privada, contribuindo para a criação de novas práticas pedagógicas ou de uma ciberpedagogia confrontando com o moduz operandi na docência. A pesquisa utilizou-se de reuniões de grupos e aplicação de questionário para professores dos cursos de Administração, Biomedicina, Contábeis, Direito, Enfermagem, Serviço Social e Zootecnia. Os dados foram interpretados por meio do círculo hermenêutico dialético (CHD). Os sentidos extraídos das falas dos docentes apontam como resultados preliminares que a TIC estimula o estudo, otimiza tempo e trabalho, favorece a autonomia do estudante e a responsabilidade.

No artigo intitulado NOMOFOBIA: os impactos psíquicos do uso abusivo das tecnologias digitais em jovens universitários os autores Irenides Teixeira, Paula 


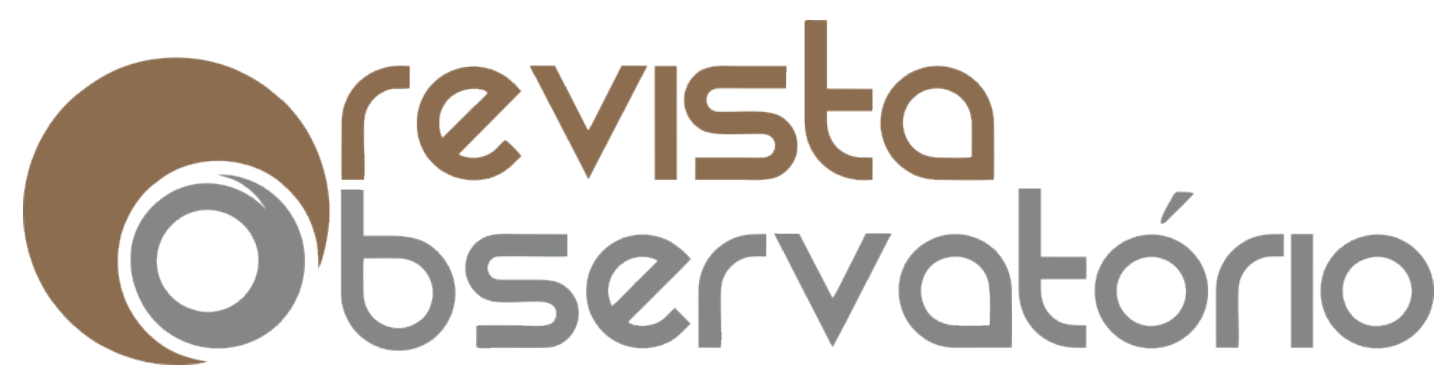

ISSN n० 2447-4266

Vol. 5, n. 5, Agosto. 2019

DOI: http://dx.doi.org/10.20873/uft.2447-4266.2019v5n5p26

Corrêa da Silva, Sonielson Luciano de Sousa e Valdirene Cássia da Silva investigam os impactos psicológicos, físicos e sociais gerados pela Nomofobia, em jovens acadêmicos de psicologia, do CEULP/ULBRA, de Palmas-TO. Tendo em vista que a Nomofobia é considerada como uma desordem do mundo contemporâneo. $O$ termo é usado para descrever o desconforto ou ansiedade causada pela não disponibilidade de um telefone celular, computador elou internet. A amostra da pesquisa consistiu em 33 acadêmicos de psicologia que aceitaram participar deste estudo, que foi realizado na Rede Social Facebook durante o período de 24 e 25 de setembro do ano 2018, após a aprovação do Comitê de Ética. Considerando ser uma pesquisa de campo e quantitativa, trabalhou com amostras de dimensões que permitiram análises estatísticas sem, no entanto, preocupar-se com a representatividade da amostra. Após a análise dos dados, buscou-se compreender e correlacionar as mudanças de comportamento à utilização da tecnologia, levantando as possíveis facilidades e dificuldades desse uso, subsidiando novos estudos para construção de uma forma diferente de abordar o problema.

No artigo intitulado VIDAS FOTOGRAFICAMENTE EDITADAS os autores Kyldes Batista Vicente e Fábio d'Abadia de Sousa discutem alguns aspectos relacionados ao uso de fotografias em redes sociais. A bordagem questiona o fato de a fotografia ser apresentada de forma geralmente editada, a fim de passar uma impressão falseada daquilo que o internauta realmente é. A discussão também chama a atenção para o fato de que as vidas perfeitas divulgadas nas fotografias pessoais postadas na rede mundial de computadores contribuem também para a implantação de preconceitos contra os que não se encaixam no padrão de aparência ditado.

O segundo dossiê, intitulado EDUCAÇÃO EMPREENDEDORA, INOVAÇÃO E DESENVOLVIMENTO REGIONAL NO NORTE DO BRASIL, inicia com O artigo intitulado IMPASSES TECNOLÓGICOS PARA GESTÃO DO CICLO BIOLÓGICO DA 


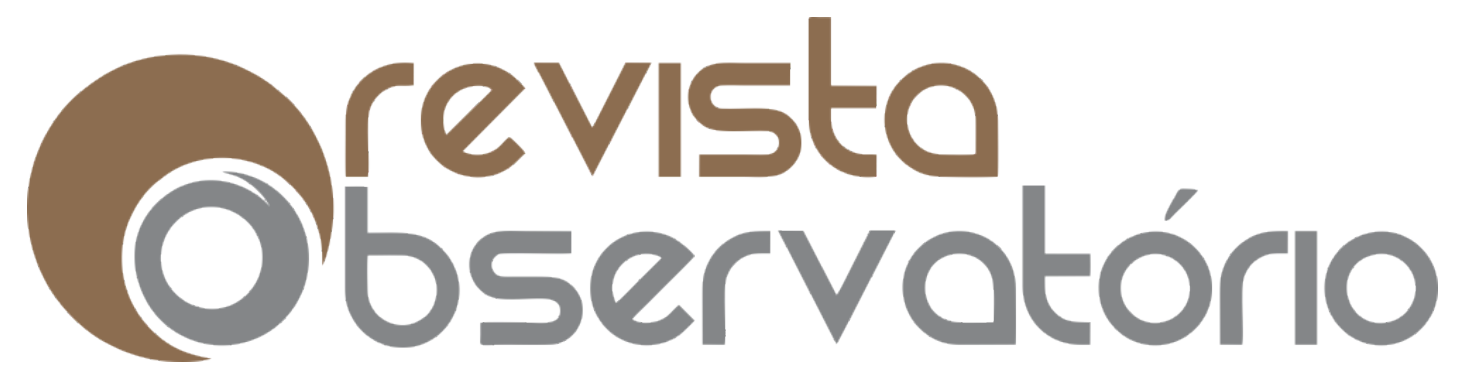

ISSN n²447-4266

Vol. 5, n. 5, Agosto. 2019

DOI: http://dx.doi.org/10.20873/uft.2447-4266.2019v5n5p26

\section{ECONOMIA CIRCULAR NA INDÚSTRIA DE PROCESSAMENTO DE CARNE BOVINA}

os autores Débora Oliveira de Souza, Maria Tereza Saraiva de Souza e Erica Lissandra Bertolossi Dantas analisam como os impasses tecnológicos dificultam a implementação do ciclo biológico da economia circular na indústria de processamento de carne bovina. O método de pesquisa foi estudo de casos múltiplos com abordagem qualitativa. Os instrumentos utilizados foram as entrevistas, pesquisa documental, observação e dados visuais. Os resultados mostram que há vários entraves tecnológicos que dificultam a implementação dos princípios da Economia Circular na indústria de processamento da carne bovina. Essas entraves estão relacionados ao consumo elevado de água e pouco uso de tecnologias eficientes no tratamento de águas residuais; à ausência de incentivos fiscais do governo para aquisição de novas tecnologias; aos altos valores tributários que dificultam a aquisição de tecnologias inovadoras; à falta de motivação e interesse dos gestores para tecnologias relacionadas ao meio ambiente; e à omissão da fiscalização de órgãos competentes.

No artigo intitulado DESENVOLVIMENTO SUSTENTAVEL, ECONOMIA CIRCULAR E EDUCAÇÃO EMPREENDEDORA os autores Maria Raquel Lucas, Isabel Joaquina Ramos e Conceição Rego discutem aspectos ligados a Economia Linear ou modelo de consumo "obter-usar-deitar fora", cujas origens datam da Revolução Industrial e que foi a base do desenvolvimento da economia global, por razões de ordem social, económica e ambiental, não é considerado sustentável. Assim, um novo modelo, o da Economia Circular, é visto como um elemento chave para promover a dissociação entre o crescimento económico e o aumento do consumo de recursos, desligando-se, assim, da Economia Linear. Apesar de muito defendidos, a Economia Circular e o Desenvolvimento Sustentável ainda não são amplamente praticados. 


\section{Obrevisto}

ISSN n² 2447-4266

Vol. 5, n. 5, Agosto. 2019

DOI: http://dx.doi.org/10.20873/uft.2447-4266.2019v5n5p26

No artigo intitulado PRODUÇÃO DA BANANA E SEUS IMPACTOS SOCIOECONÔMICOS NO DESENVOLVIMENTO DA MICRORREGIÃO DE ARAGUAÍNA-TO os autores Kleber Abreu Sousa, Maria Raquel Lucas, Débora Oliveira de Souza e Beatriz Batista Costa investigam a produção da banana, destacando suas transformações e seus impactos socioeconômicos no desenvolvimento da microrregião de Araguaína-TO. O trabalho se classifica como estudo de caso, baseado em revisão bibliográfica, com abordagem qualitativa de natureza exploratória e descritiva, buscando a compreensão e a descrição dos elos da cadeia produtiva. Quanto aos resultados, pode-se perceber o melhoramento da produção a partir das técnicas de manejo utilizadas nas etapas do processo de produção da bananicultura, bem como os benefícios adquiridos na região por meio da atividade agrícola e contribuindo assim o desenvolvimento econômico e social da região.

No artigo intitulado A INFLUÊNCIA DOS YOUTUBERS DO SEGMENTO DA BELEZA SOBRE PRÁTICAS DE CONSUMO NO CENÁRIO PALMENSE os autores Suzana Gilioli da Costa Nunes, Marcelo Barbosa e André Gonzaga Aires avaliam o comportamento dos consumidores na decisão de compra perante a influência dos YouTubers, referente ao segmento da beleza no mercado da cidade de Palmas TO. O método da pesquisa foi uma análise quantitativa para dados qualitativos, sendo assim uma pesquisa qualitativa com análise de dados quantitativos, do tipo descritiva. Foram abordados 225 entrevistados em 26 horas, dentro do munícipio. A análise dos dados foi feita a partir de um perfil traçado de cada consumidor, após isso foi feito o cruzamento desses perfis, que resultou em fatores de similaridades e diferenciação entre eles, onde apontou a forma como os influenciadores digitais e seus vídeos impactam esses consumidores.

No artigo intitulado A UTILIZAÇÃO DAS MÍDIAS SOCIAIS NO PROCESSO DE PLANEJAMENTO DE VIAGENS os autores Heliney Nunes Resende Junior, Suzana 


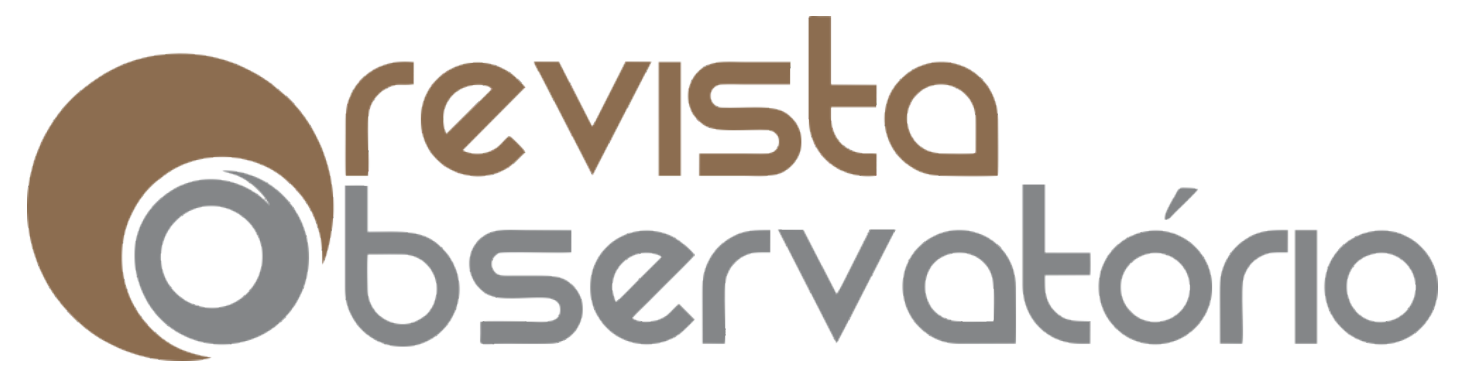

ISSN n² 2447-4266

Vol. 5, n. 5, Agosto. 2019

DOI: http://dx.doi.org/10.20873/uft.2447-4266.2019v5n5p26

Gilioli da Costa Nunes e Alain Santoyo mensuram a influência das mídias sociais no processo de planejamento de viagens em relação a população da cidade de Palmas, capital do estado do Tocantins. A metodologia utilizada nessa pesquisa foi uma avaliação quantitativa a partir da aplicação de questionário. A amostra da pesquisa foi composta de 500 respondentes. A análise dos resultados mostrou que as mídias sociais já têm grande influência no processo de planejamento de viagens e que tem um espaço para um crescimento ainda maior, pois as mídias sociais estão em constante evolução de acordo com as necessidades as pessoas. A pesquisa também apontou que as pessoas confiam nas informações obtidas através das mídias e estão deixando de acreditar cada vez mais nos meios de comunicação convencionais.

No artigo intitulado PESQUISA DE SATISFAÇÃO COM ACADÊMICOS DO CURSO DE TECNOLOGIA EM LOGÍSTICA EM RELAÇÃO AOS PROFESSORES E INFRAESTRUTURA DO CAMPUS os autores Kleber Abreu Sousa, Elizabeth Aparecida Corrêa Menezes e Kelly Cristina Dos Santos Lima avaliaram o nível de satisfação dos acadêmicos do curso de Tecnologia em Logística da Universidade Federal do Tocantins; e também, busca analisar elementos ligados a satisfação dos discentes quanto à organização institucional, o corpo docente e a infraestrutura física. Quanto à natureza da pesquisa, este trabalho recorreu à pesquisa de campo e bibliográfica, em forma quali-quantitativa. Quanto aos resultados desse estudo foi comprovado que os acadêmicos demonstraram satisfação.

No artigo intitulado AJUDE-ME POR FAVOR! O efeito da cocriação na persuasão de consumidores os autores Warton da Silva Souza, Melby Karina Zuniga Huertas, Fábio Rogério de Morais e Juliana Moreira Batista fazem uma revisão da literatura sobre cocriação detectou-se lacunas teóricas relacionadas à resposta do consumidor observador (que não participou do processo de cocriação) aos resultados da cocriação. O objetivo desta pesquisa é estudar o efeito de se 


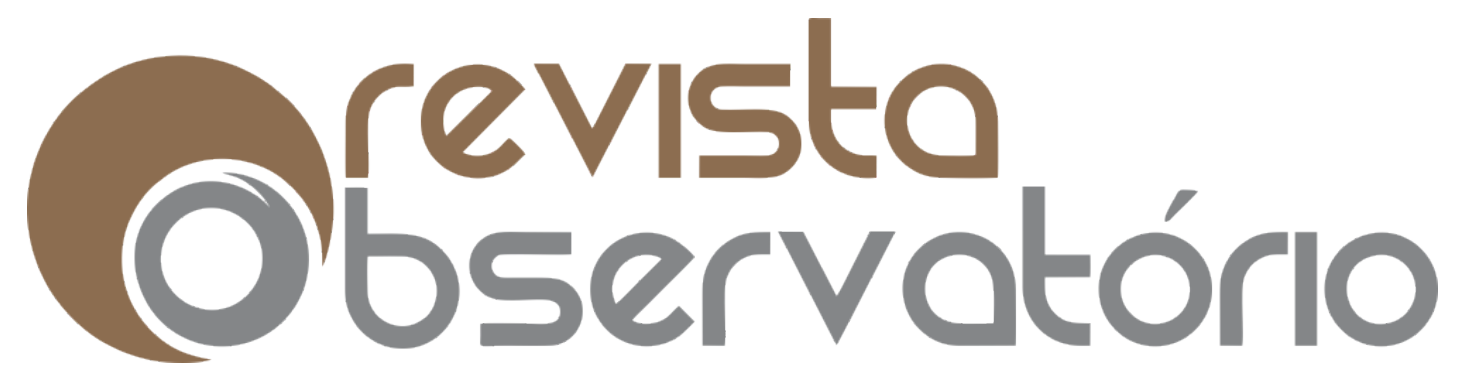

ISSN n²447-4266

Vol. 5, n. 5, Agosto. 2019

DOI: http://dx.doi.org/10.20873/uft.2447-4266.2019v5n5p26

informar a cocriação (empresa/consumidor e empresa/especialista) do produto, na persuasão do consumidor observador, considerando-se diferentes apelos de propaganda. Em 2 experimentos foram manipuladas as variáveis "tipo de parceiro de cocriação" (consumidores/ especialistas) e "tipo de apelos da mensagem" (racionais/emocionais).

Na seção TEMAS LIVRES, iniciamos com o artigo intitulado EVASÃO NO CURSO DE LICENCIATURA EM FÍSICA DA UNIVERSIDADE FEDERAL DO TOCANTINS: diagnóstico e primeiros resultados de um projeto de intervenção os autores Erica Cupertino Gomes, Denisia Brito Soares, Shirlei Nabarrete Desidério e Alexsandro Silvestre da Rocha analisam um curso na Universidade Federal do Tocantins (UFT) e apresentam um diagnóstico sobre a relação entre a oferta de professores de Física e a formação de estudantes em Nível Médio. As análises apontam para a incapacidade do Sistema de Ensino Superior em suprir a demanda de professores, o que implica quanti e qualitativamente na formação científica dos estudantes brasileiros. $O$ diagnóstico mostra a necessidade da intervenção e avalia os primeiros dados do Programa Institucional de Apoio ao Discente Ingressante sobre uma das disciplinas do Currículo do Curso. Os primeiros resultados mostram um impacto significativo na evasão dos estudantes.

No artigo intitulado BH 102 FM: uma trajetória construída a partir da audiência os autores Debora Cristina Lopez e Matheus Maritan analisam a trajetória da Rádio BH 102 FM desde o seu surgimento até os dias atuais. Organizamos o texto em dois eixos: os marcos históricos construídos em antena e no ambiente online. Consideramos que a entrada da emissora nas plataformas digitais não a retirou do dial, mas alterou seu foco de produção, dando multiplicidade ao conteúdo e modificando o padrão de ação dos comunicadores. Consideramos nesta etapa a entrada da BH FM nas redes sociais, nos aplicativos 


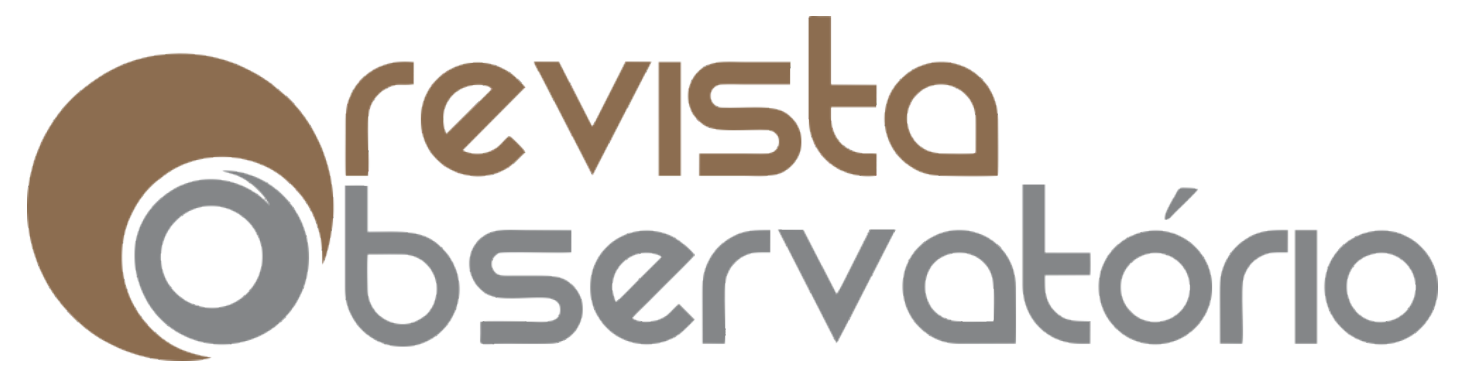

ISSN n² 2447-4266

Vol. 5, n. 5, Agosto. 2019

DOI: http://dx.doi.org/10.20873/uft.2447-4266.2019v5n5p26

para dispositivos móveis e a criação de seu suporte digital mais essencial, o site. Utilizamos o método da entrevista semi-estruturada e nos apropriamos da ferramenta Way Back Machine para compreender as principais transformações pelas quais o veiculo passou ao longo da sua história.

No artigo intitulado SÉRIES TELEVISIVAS BRASILEIRAS: A NARRATIVA E A RESSIGNIFICAÇÃO DA HISTÓRIA RECENTE NACIONAL EM "OS DIAS ERAM ASSIM" os autores Humberto Junio Alves Viana, Christina Ferraz Musse e Talita Souza Magnolo discutem a ressignificação da história recente do Brasil e do papel da Rede Globo na construção dessa memória são um dos motes narrativos da supersérie "Os dias eram assim", que estreou na emissora, no dia 17 de abril de 2017. O período ditatorial brasileiro foi cenário para a história de amor dos protagonistas. Entretanto, a velha fórmula de sucesso, melodramática e folhetinesca, ganha nova roupagem quando rememora os anos de exceção, a partir daquilo que a emissora, na época, escondeu: as graves violações aos direitos humanos e a ampla participação da sociedade civil. $\mathrm{Na}$ análise, percebeu-se que no ritual de rememoração, ao mesclar imagens de arquivo dos telejornais à narrativa ficcional, a Rede Globo, por meio dessa hibridização, não só ressignificou a história, como também o seu lugar de fala.

No artigo intitulado UMA ANÁLISE DA IMPORTÂNCIA DAS PATENTES RELACIONADAS AO SOFTWARE os autores Rafael Lima de Carvalho, Tiago Almeida da Silva e Fabrício Barros Gonçalves buscaram verificar quais as classes de patentes que a IBM concentrou mais ativos no ano de 2017. Como resultado, descobriu-se que mais de $25 \%$ das patentes estão relacionadas com classes que envolvem software. Por fim, o presente trabalho elenca alguns pontos positivos e negativos sobre proteção de software através de patentes no Brasil

No artigo intitulado IMAGOLOGIA ROBÓTICA: robôs e inteligência artificial nas narrativas para crianças e jovens $O$ autor Pedro Gabriel D'Alte que discute as 


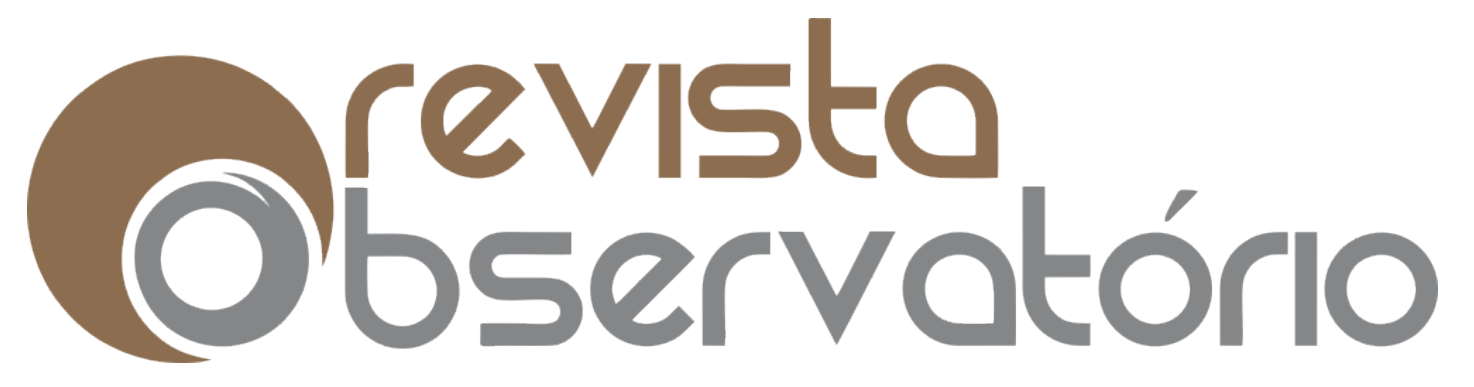

ISSN n०2447-4266

Vol. 5, n. 5, Agosto. 2019

DOI: http://dx.doi.org/10.20873/uft.2447-4266.2019v5n5p26

narrativas para a infância e juventude que absorvem os discursos sobre a inteligência artificial e, por meio de processos literários abeirados ora de um certo mimetismo ora da mais virtuosa reconfiguração da realidade, apresentam cenários que convidam o leitor, desde tenra idade, a repensar um mundo permeado pelo digital. As narrativas escolhidas para o presente exercício intelectual intentam demonstrar um caleidoscópio de imagens variado e que dê conta de diferentes perspetivas face à inteligência artificial promovendo, desta forma, um exercício crítico e exploratório sobre a mesma.

No artigo intitulado BEST-SELLERS DA DITADURA: os livros mais vendidos sob o Al-5 a autora Eliane Hatherly Paz que discute e mapeia os livros mais vendidos entre dezembro de 1968 e dezembro de 1978 decênio em que vigorou o Ato Institucional $n^{\circ} 5$, o qual instaurou, entre outras medidas ditatoriais, a censura prévia aos livros - para responder à pergunta: o que liam os brasileiros sob o Al-5? A fonte serão as listas de best-sellers da revista Veja, semanário de notícias lançado em setembro de 1968, cuja evolução gráfica e relevância no periódico também estão aqui registradas. Como aporte teórico, recorrerei às reflexões de Robert Darnton e Pierre Bourdieu sobre o campo editorial.

No artigo intitulado INTEGRAÇÃO DO PROCESSO DE PLANEJAMENTO E ORÇAMENTO POR MEIO DO SISTEMA SIE OS autores Eduardo Andrea Lemus Erasmo, Michelle Duarte e Jaasiel Nascimento Lima discutem a integração na Universidade Federal do Tocantins - UFT, como uma forma de aprimorar a execução do orçamento destinado à UFT e ampliar o controle de seus dispêndios, com a finalidade de atender o que foi proposto no Plano de Desenvolvimento Institucional. Nesse contexto, o presente estudo tem como objetivo apresentar a sistemática utilizada pela Universidade Federal do Tocantins - UFT para integração entre o planejamento institucional e o orçamento disponibilizado para 


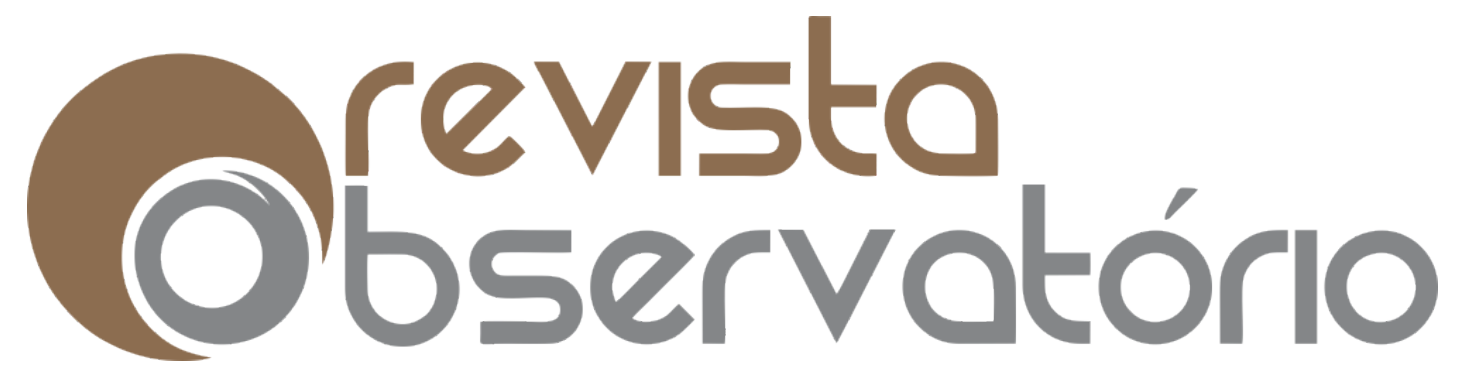

ISSN n² 2447-4266

Vol. 5, n. 5, Agosto. 2019

DOI: http://dx.doi.org/10.20873/uft.2447-4266.2019v5n5p26

financiamento das ações, sendo este uma ferramenta no processo de tomada de decisão e otimização da gestão. Essa integração foi realizada por meio do sistema SIE - Sistema de Informações para o Ensino, projeto que começou a ser desenvolvido pela Universidade de Santa Maria (UFSM), com apoio da Secretaria de Ensino Superior (SESu) do Ministério da Educação (MEC). A adoção do modelo melhorou o processo de planejamento já existente dentro da instituição, como também proporcionou a abertura de um novo paradigma na gestão orçamentária, com apontamento para uma gestão descentralizada.

No artigo intitulado DESAFIOS GERADOS PELO CRESCIMENTO POPULACIONAL URBANO NO CONTEXTO DAS CIDADES INTELIGENTES os autores Mauricio Santana Ribeiro, Rafael Lima de Carvalho, Ary Henrique M. Oliveira, Glenda Michele Botelho e Wandson Mendes Pessoa discutem as cidades inteligentes, que são definidas como um novo método para o desenvolvimento sustentável das cidades. Este artigo analisa as concepções conceituais quanto às cidades inteligentes comparado ao crescimento populacional urbano das cidades e discutindo se o processo de expansão territorial e a verticalização das cidades. A problemática desenvolvida procura discutir se de fato as cidades inteligentes são o caminho para o preparo do crescimento populacional. Os resultados mostram que há significativa hipótese para essa condição.

No artigo intitulado RESPONSABILIDADE SOCIAL EMPRESARIAL, EMPREENDEDORISMO SOCIAL E ECONOMIA SOLIDÁRIA: similitudes, ambivalências e possíveis conexões $\mathrm{O}$ autor Edson Marques Oliveira discute aspectos ligados a crise mundial deflagrada em 2008, pela especulação financeira, que serviu para acentuar nos países ricos o que os países pobres já vêm enfrentando a muitas décadas, recessão, inflação, desemprego, desigualdade, exclusão social, violência, entre outras mazelas sociais. E no epicentro das grandes demandas surgem alternativas de enfrentamento, sejam oriundas dos governos, 


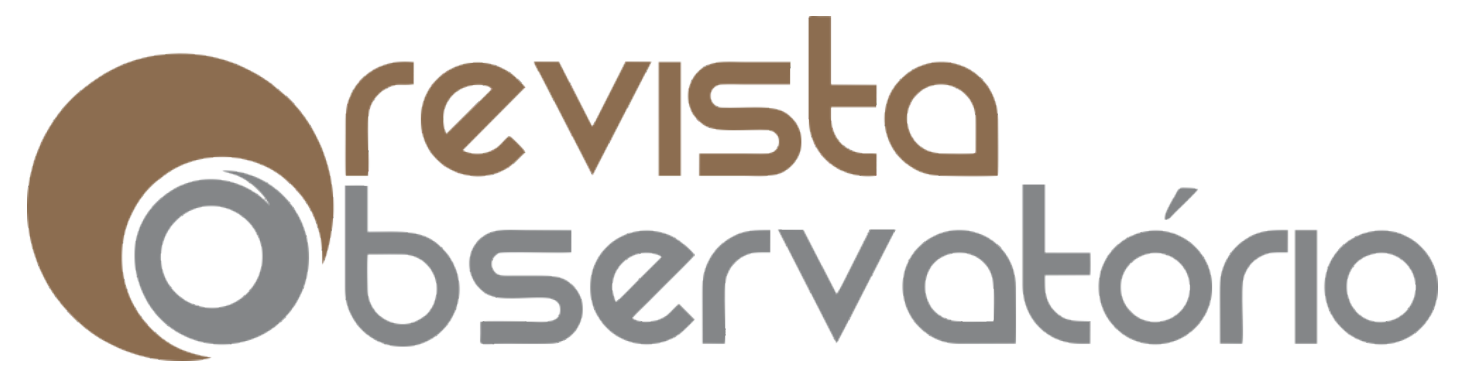

ISSN n² 2447-4266

Vol. 5, n. 5, Agosto. 2019

DOI: http://dx.doi.org/10.20873/uft.2447-4266.2019v5n5p26

das organizações empresariais ou da sociedade civil organizada, a essa tríade tem se denominado de primeiro setor (governo) segundo setor (empresas privadas) e terceiro setor (sociedade civil). É sobre isso que o presente artigo trata. De uma análise a partir de dados empíricos de uma pesquisa referente ao perfil de organizações empresarias da região Oeste do Paraná, Brasil, da prática de um projeto de extensão e da participação de organizações da sociedade civil, e empresarial na criação e desenvolvimento de ações de intervenção no campo da responsabilidade social empresarial, do Empreendedorismo Social, e mais recentemente no viés da economia solidaria. E com isso apontar as possíveis conexões, ambivalências e inflexões necessárias para melhor compreensão desse momento e processo.

No artigo intitulado EL MUSEO FUERA Y DENTRO DEL AULA DE PRIMARIA o autor Víctor Manuel Amar Rodríguez discute as utilizações do espaço museal para a educação. A defesa do autor é que o museu não pode ser só um lugar para admirar a arte. Com um bom desenho se converteria num excelente pretexto para inovar e indagar. Professorado e alunado têm muito a dizer. Inclusive, pode se apropriar do conteúdo dum quadro, pode representar a mensagem duma escultura, aliás, de compartilha-lo com o resto de seus companheiros na escola. 0 museu fora e dentro da aula de primária é um bom motivo para ensinar e para aprender, para trabalhar em equipe, para abrir a mente e reflexionar ou crescer em responsabilidade cidadã.

No artigo intitulado EXPERIÊNCIAS EM MUSEUS POSSUEM A CAPACIDADE DE EVOCAR LEMBRANÇAS EM UM PÚBLICO DE TERCEIRA IDADE? os autores Ana Luiza Santos Tizzo e Daniela Franco Carvalho apresentam aspectos ligados ao envelhecimento. $\mathrm{O}$ que o envelhecimento traz de bonito, é que idosos adquirem sua própria bagagem ao longo de toda a sua vivência. As experiências vividas, são guardadas em um museu peculiar, seu próprio corpo. É de grande importância 


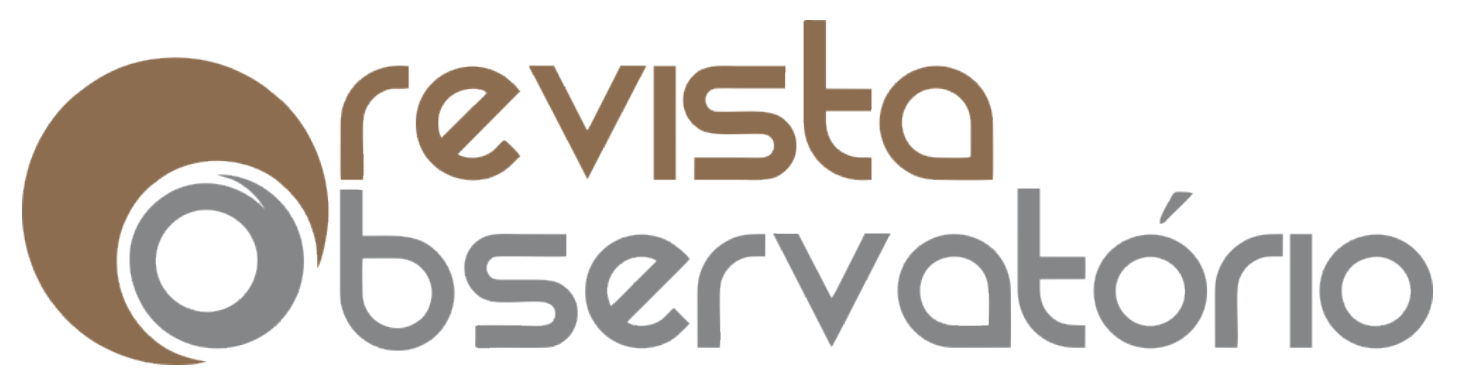

ISSN n० 2447-4266

Vol. 5, n. 5, Agosto. 2019

DOI: http://dx.doi.org/10.20873/uft.2447-4266.2019v5n5p26

transmitir toda a sabedoria e experiência adquirida, pois só assim teremos a arte do encontro. No entremeio dessas memórias, os museus se tornam instrumentos de evocação. Por meio de encontros e diálogos em um artefato museal, a casinha de pau-a-pique possibilitou, potencializou, despertou e provocou experiências e reflexões do ontem no hoje.

No artigo intitulado INOVAÇÃO VERDE: Produtos e processos como fator de vantagem competitiva os autores Seimor Walchhutter, Eduardo Kalil Hanna e Warton da Silva Souza analisam em que medida a inovação verde se constitui como fator de vantagem competitiva para as organizações. Foi realizado um estudo quantitativo em uma indústria do setor automotivo para relacionar os resultados entre inovação de produtos e processos verdes com a vantagem competitiva. Os resultados da pesquisa demostram que há correlação positiva entre produtos verdes e vantagem competitiva, entretanto, não há correlação positiva entre processos verdes e vantagem competitiva confirmando uma das hipóteses da pesquisa.

No artigo intitulado VISIBILIDADE DOS PEQUENOS NEGÓCIOS NA IMPRENSA TOCANTINENSE: estudo de caso da assessoria de imprensa do SEBRAE Tocantins os autores Layala Cardoso da Silva Istofel e Darlene Teixeira Castro descrevem como o ciclo jornalístico - produção de releases, distribuição, follow up, análise do clipping e ajustes - pode, se bem conduzido, despertar o interesse da mídia, agregando valor para a instituição e seus clientes. Busca-se ainda mapear os veículos de comunicação que mais deram visibilidade para os pequenos negócios no Tocantins a partir da análise da série histórica da produção dos releases e da mídia espontânea do SEBRAE-TO no período de 2005/2015.

No artigo intitulado GÊNERO E RAÇA NA COMUNICAÇÃO DE MARCAS: A dimensão política do consumo sob uma perspectiva interseccional os autores Pablo Moreno Fernandes Viana e Dalila Maria Musa Belmiro analisam a 


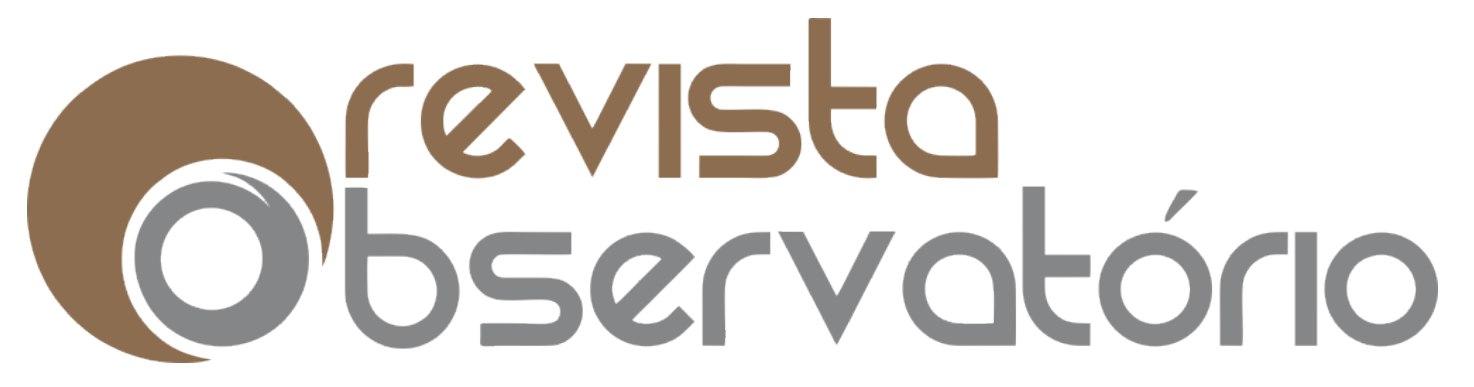

ISSN n² 2447-4266

Vol. 5, n. 5, Agosto. 2019

DOI: http://dx.doi.org/10.20873/uft.2447-4266.2019v5n5p26

comunicação de marcas que comercializam produtos para cabelos cacheados e crespos em comemoração ao Dia Internacional da Mulher e Dia da Consciência Negra em 2018. Baseados na origem das duas datas, estudamos as dimensões políticas do consumo, a partir de uma perspectiva interseccional entre gênero e raça. A análise semiótica de posts no Facebook de três marcas brasileiras discute a constituição da identidade das mulheres negras, seu lugar na sociedade, assim como empoderamento e consumo na contemporaneidade, em um país sexista e racista. Verificamos como as interseccionalidades são abordadas (ou apagadas), em um cenário que visa inserir negros nos discursos publicitários.

No artigo intitulado INTERDISCIPLINARIDADE, CRITICIDADE E FORMAÇÃO SOCIOAMBIENTAL NA UNIVERSIDADE os autores Nelson Russo de Moraes, Fernando da Cruz Souza, Cristiane Teixeira Bazílio Marchetti, Felipe Góes de Moraes e Joicileia Juliate Fonseca desenvolvem esta comunicação científica que desdobrase dos trabalhos desenvolvidos no GEDGS (Grupo de Estudos em Democracia e Gestão Social) da UNESP a partir da tese e textos de defesa de linha de pesquisa para a obtenção do título de livre-docente em Gestão e Educação Ambiental.

No artigo intitulado ESTADO DE BEM-ESTAR SOCIAL: UMA REVISÃO DE LITERATURA os autores Fernando da Cruz Souza e Nelson Russo de Moraes que desenvolvem uma revisão bibliográfica convencional sobre o Estado de Bem-Estar Social, elencando a partir dela as razões históricas de seu surgimento, a tipologia de Esping-Andersen, a noção de funcionamentos e capacitações de Amartya Sen e os períodos constitutivos do bem-estar no Brasil.

No artigo intitulado UNIDADE PRISIONAL FEMININA DE PALMAS: Conselho de Classe Participativo os autores Adriana da Costa Pereira Aguiar e Rosilene Lagares analisam como acontece o conselho de classe na unidade de ensino prisional feminino de Palmas. Utilizou-se o método da História Oral Temática com entrevistas semiestruturadas. $\mathrm{O}$ estudo se apresenta respondendo a três objetivos 


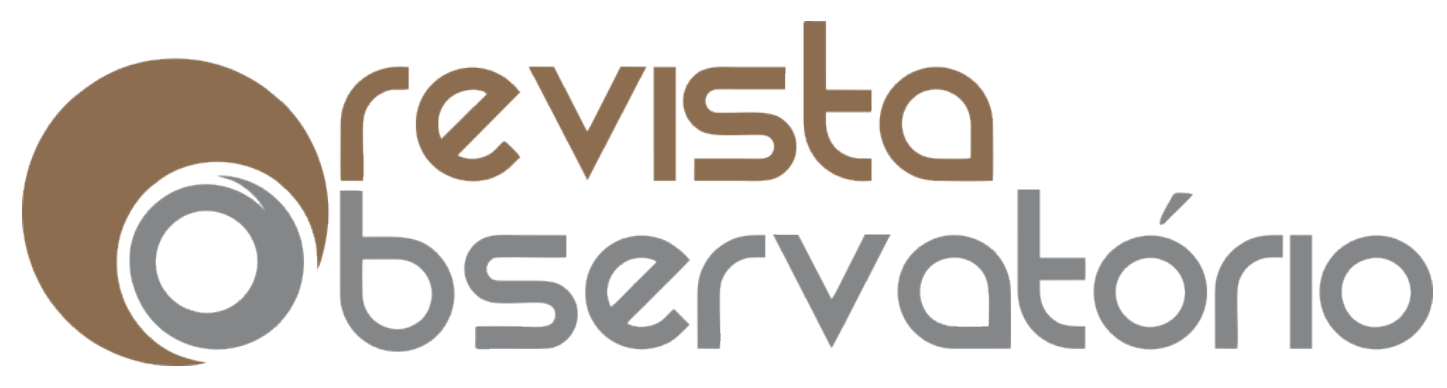

ISSN n² 2447-4266

Vol. 5, n. 5, Agosto. 2019

DOI: http://dx.doi.org/10.20873/uft.2447-4266.2019v5n5p26

específicos, sendo: traçar um breve percurso histórico da educação prisional feminina no Tocantins; conhecer o trabalho educacional dentro da prisão feminina; narrar os depoimentos das entrevistadas.

No artigo intitulado TECNOLOGIAS DIGITAIS E EDUCAÇÃO: impactos e desafios para uma nova configuração de subjetividade os autores Elaine Moraes Santos e Luiz Antonio Calmon Nabuco Lastória problematizam à luz da Teoria Crítica da Sociedade os impactos e desafios que o atual regime de vida apoiado no uso das tecnologias digitais traz para o campo da educação, com o intuito de que esta investigação possibilite um novo olhar metodológico sobre a utilização destes recursos em prol de um ambiente escolar que reconecte o espaço alargado entre os tradicionais moldes de ensino e a nova subjetividade e identidade contemporânea do alunado.

Já o artigo intitulado TECNOLOGIAS EDUCACIONAIS: representações sociais de professores indígenas em formação os autores Aldrin Cleyde da Cunha e Janielle da Silva Melo da Cunha descrevem e analisam as representações sociais dos acadêmicos indígenas sobre o uso das tecnologias educacionais para o ensino e aprendizagem de ciências e matemática na formação inicial de professores indígenas.

No artigo intitulado OS OLHARES DA COMUNICAÇÃO ORGANIZACIONAL NO BRASIL PARA O ENSINO SOB O PARADIGMA DA COMPLEXIDADE, de Luciana Santos Almeida Theodoro e Francisco Gilson Rebouças Porto Junior, apresentam como o termo Paradigma da Complexidade tem aparecido nos artigos publicados nos Anais do Congresso da Abrapcorp, o mais representativo da área no Brasil.

E, por fim, no artigo intitulado A REIFICAÇÃO DA MULHER E A OFENSIVA CONSERVADORA NO BRASIL ATUAL, João Nunes da Silva e Enza Rafaela Peixoto Ferreira refletem sobre a categoria da reificação nos sujeitos femininos diante de 


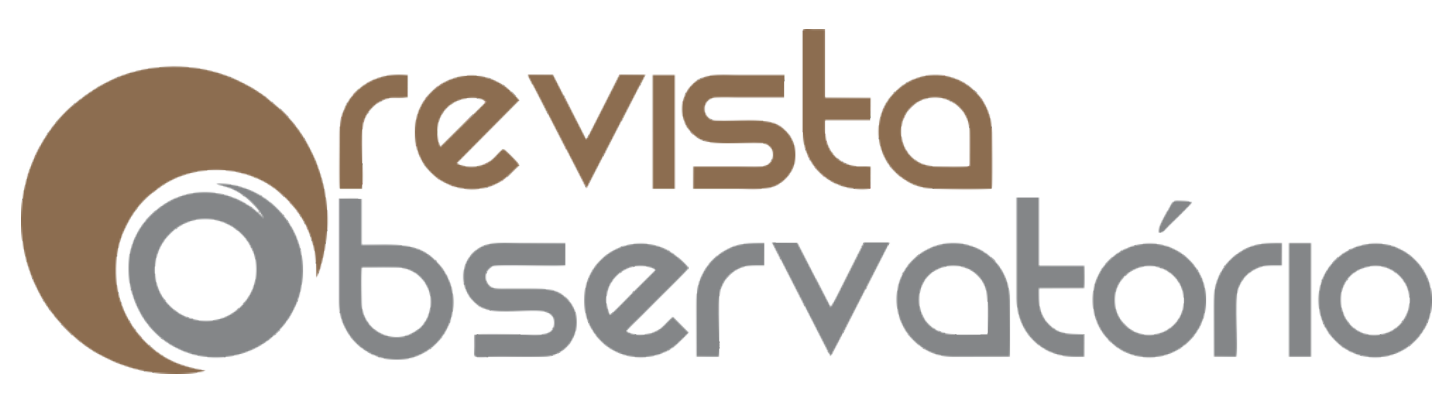

ISSN n² 2447-4266

Vol. 5, n. 5, Agosto. 2019

DOI: http://dx.doi.org/10.20873/uft.2447-4266.2019v5n5p26

um cenário de ofensiva conservadora e sexista que emerge no atual momento brasileiro com foco na exploração e dominação às mulheres.

Sejam todos/as bem-vindos/as as temáticas deste número! Leia, compartilhe e indique a leitura dos artigos produzidos no n. 5 de 2019 da Revista Observatório.

Palmas, TO, Salvador-BA e Tupã-SP , agosto de 2019.

Editores convidados/ Guest Editors/ Editores invitados

Profa. Dra. Valdirene Cássia Silva, Faculdade Católica do Tocantins (FACTO), Brasil.

Profa. Dra. Irenides Teixeira, Centro Universitário Luterano de Palmas (CEULP-ULBRA), Brasil.

Prof. Dr. Edvaldo Couto, Universidade Federal da Bahia (UFBA), Brasil.

Profa. Dra. Liana Vidigal, Universidade Federal do Tocantins (UFT), Brasil.

Prof. Dr. Kleber Abreu Sousa, Universidade Federal do Tocantins (UFT), Brasil.

Editor Geral / Chief Editor / Editor general

Prof. Dr. Nelson Russo de Moraes, Universidade Estadual Paulista Júlio de Mesquita Filho (UNESP), Brasil.

Prof. Dr. Francisco Gilson Rebouças Porto Junior, Universidade Federal do Tocantins (UFT), Brasil. 


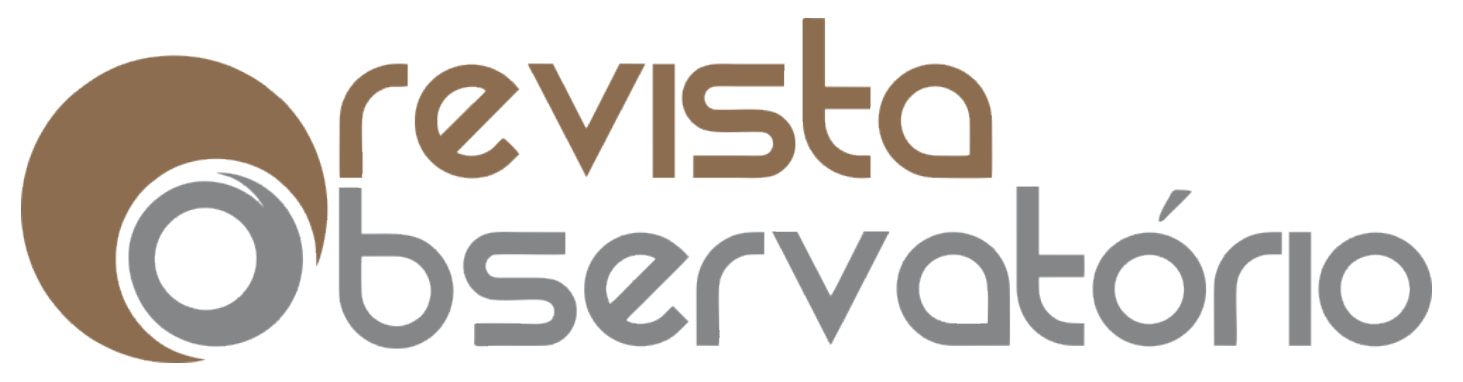

ISSN n० 2447-4266

Vol. 5, n. 5, Agosto. 2019

DOI: http://dx.doi.org/10.20873/uft.2447-4266.2019v5n5p26

\section{Referências}

AGUIAR, A. DA C. P.; LAGARES, R. UNIDADE PRISIONAL FEMININA DE PALMAS: Conselho de Classe Participativo. Revista Observatório, v. 5, n. 5, 1 ago. 2019..

BERNARDO, C. H. C.; BRAGA JÚNIOR, S. S.; MARQUES, M. D.; GOMES, S. C. V.; QUEIROZ, T. R. Percepção dos produtores rurais de Tupã, SP, sobre o processo de comunicação para execução da logística reversa de embalagens de agrotóxicos. Revista Observatório, v. 1, n. 3, p. 242-270, 26 dez. 2015.

BUENO, T. C.; REINO, L. S. A. ENTRE A TABLOIDIZAÇÃO E O TEASER PUBLICITÁRIO: uma análise dos títulos caça-cliques. Revista Observatório, v. 4, n. 3, p. 675-707, 29 abr. 2018.

CARNIGLIA, E. L.; TAMARGO, C. B. ANTES DEL ALUVIÓN DIGITAL: los formadores de una escuela rurbana en la transición de la informática educativa . Revista Observatório, v. 5, n. 5, 1 ago. 2019.

CHIECHER, A. C.; FICCO, C. R.; PAOLONI, P. V.; GARCÍA, G. A. ¿Qué mueve a los estudiantes exitosos? Metas y motivaciones de universitarios en las modalidades presencial y distancia. Revista Observatório, v. 2, n. 2, p. 301-326, 30 maio 2016.

CUNHA, A. C. DA; CUNHA, J. DA S. M. TECNOLOGIAS EDUCACIONAIS: representações sociais de professores indígenas em formação . Revista Observatório, v. 5, n. 5, 1 ago. 2019..

D'ALTE, P. G. IMAGOLOGIA ROBÓTICA: robôs e inteligência artificial nas narrativas para crianças e jovens. Revista Observatório, v. 5, n. 5, 1 ago. 2019..

DE CARVALHO, R. L.; DA SILVA, T. A.; GONÇALVES, F. B. UMA ANÁLISE DA IMPORTÂNCIA DAS PATENTES RELACIONADAS AO SOFTWARE. Revista Observatório, v. 5, n. 5, 1 ago. 2019..

ELHAJJI, M.; ESCUDERO, C. WEBDIÁSPORA: Migrações, TICs e memória coletiva. Revista Observatório, v. 2, n. 5, p. 334-363, 25 dez. 2016.

ERASMO, E. A. L.; DUARTE, M.; LIMA, J. N. INTEGRAÇÃO DO PROCESSO DE PLANEJAMENTO E ORÇAMENTO POR MEIO DO SISTEMA SIE. Revista Observatório, v. 5, n. 5, 1 ago. 2019..

EVANGELISTA, F.; MARTINS, K. D.; ANGELINI, M. F. C.; ROCHA, M. J. F. SOCIEDADE DO CONHECIMENTO: O uso das TIC por docentes e as novas articulações de saberes educacionais no sudeste do Pará. Revista Observatório, v. 5, n. 5, 1 ago. 2019.

FERNANDES VIANA, P. M.; MUSA BELMIRO, D. M. GÊNERO E RAÇA NA COMUNICAÇÃO DE MARCAS: A dimensão política do consumo sob uma perspectiva interseccional. Revista Observatório, v. 5, n. 5, 1 ago. $2019 .$.

GOMES, E. C.; SOARES, D. B.; DESIDÉRIO, S. N.; ROCHA, A. S. DA R. S. DA. EVASÃO NO CURSO DE LICENCIATURA EM FÍSICA DA UNIVERSIDADE FEDERAL DO 


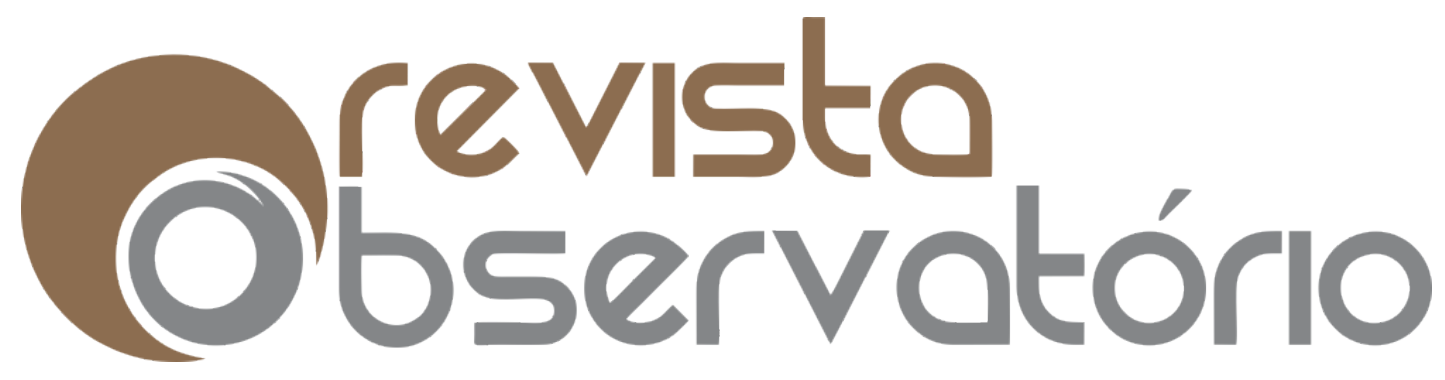

ISSN n² 2447-4266

Vol. 5, n. 5, Agosto. 2019

DOI: http://dx.doi.org/10.20873/uft.2447-4266.2019v5n5p26

TOCANTINS: diagnóstico e primeiros resultados de um projeto de intervenção. Revista Observatório, v. 5, n. 5, 1 ago. 2019..

ISTOFEL, L. C. DA S.; CASTRO, D. T. VISIBILIDADE DOS PEQUENOS NEGÓCIOS NA IMPRENSA TOCANTINENSE: estudo de caso da assessoria de imprensa do SEBRAE Tocantins . Revista Observatório, v. 5, n. 5, 1 ago. 2019..

SILVA, J. N. DA; FERREIRA, E. R. P. A REIFICAÇÃO DA MULHER E A OFENSIVA CONSERVADORA NO BRASIL ATUAL. Revista Observatório, v. 5, n. 5, p. 1022-1046, 1 ago. 2019.

LOPEZ, D. C.; MARITAN, M. BH 102 FM: uma trajetória construída a partir da audiência. Revista Observatório, v. 5, n. 5, 1 ago. 2019.

LUCAS, M. R.; RAMOS , I. J. R.; REGO , C. DESENVOLVIMENTO SUSTENTAVEL, ECONOMIA CIRCULAR E EDUCAÇÃO EMPREENDEDORA. Revista Observatório, v. 5, n. 5, 1 ago. 2019.

MACHADO, L. S.; COSTA, T. K. DE L.; MORAES, R. M. DE. MULTIDISCIPLINARIDADE E O DESENVOLVIMENTO DE SERIOUS GAMES E SIMULADORES PARA EDUCAÇÃO EM SAÚDE. Revista Observatório, v. 4, n. 4, p. 149-172, 29 jun. 2018.

MARTINS , J. L. EDUCAR NO PRESENTE EFÊMERO PARA UM FUTURO INCERTO. Revista Observatório, v. 5, n. 5, 1 ago. 2019.

MELO, A. S. E. ENQUADRAMENTO HISTÓRICO LEGAL DO PROCESSO DE BOLONHA E O SEU IMPACTO NO SISTEMA DE ENSINO SUPERIOR PORTUGUÊS. Revista Observatório, v. 3, n. 6, p. 75-141, 1 out. 2017.

MENEZES, E. A. C.; SOUSA, K. A.; LIMA, K. C. D. S. PESQUISA DE SATISFAÇÃO COM ACADÊMICOS DO CURSO DE TECNOLOGIA EM LOGÍSTICA EM RELAÇÃO AOS PROFESSORES E INFRAESTRUTURA DO CAMPUS. Revista Observatório, v. 5, n. 5, 1 ago. 2019.

MIRANDA-PINTO, M. S.; MONTEIRO, A. F.; OSÓRIO, A. J. POTENCIALIDADES E FRAGILIDADES DE ROBÔS PARA CRIANÇAS EM IDADE PRÉ ESCOLAR: 3 A 6 ANOS. Revista Observatório, v. 3, n. 4, p. 302-330, 1 jul. 2017.

MIRANDA, J. C.; SOUSA, S. L. DE. MÍDIA COMO CATALIZADORA DE DISCURSOS PÓS-MODERNOS PARA OS JOVENS. Revista Observatório, v. 5, n. 5, 141 ago. 2019. MORAES, N. R. DE; SOUZA, F. DA C.; MARCHETTI, C. T. B.; MORAES , F. G. DE; FONSECA, J. J. INTERDISCIPLINARIDADE, CRITICIDADE E FORMAÇÃO SOCIOAMBIENTAL NA UNIVERSIDADE . Revista Observatório, v. 5, n. 5, 1 ago. 2019.

MOURA, A. METODOLOGIAS DE APRENDIZAGEM QUE DESAFIAM OS ALUNOS, MEDIADAS POR TECNOLOGIAS DIGITAIS. Revista Observatório, v. 3, n. 4, p. 256278, 1 jul. 2017.

NEJM, R.; RIBEIRO, J. C. EXPOSIÇÃO DE SI NOS AMBIENTES DIGITAIS E OS DESAFIOS NA COORDENAÇÃO DAS REGRAS DE PRIVACIDADE. Revista Observatório, v. 5, n. 5, 1 ago. 2019. 


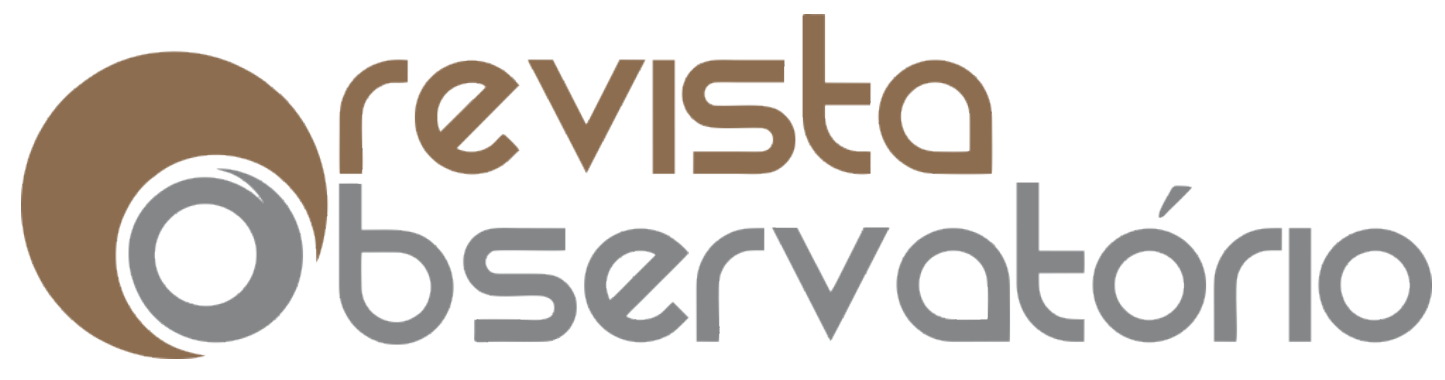

ISSN n² 2447-4266

Vol. 5, n. 5, Agosto. 2019

DOI: http://dx.doi.org/10.20873/uft.2447-4266.2019v5n5p26

NUNES, S. G. DA C.; AIRES, A. G.; BARBOSA, M. A INFLUÊNCIA DOS YOUTUBERS DO SEGMENTO DA BELEZA SOBRE PRÁTICAS DE CONSUMO NO CENÁRIO PALMENSE . Revista Observatório, v. 5, n. 5, 1 ago. 2019..

NUNES, S. G.; PORTO JUNIOR, F. G. R.; MORAES, N. R. DE. CONHECIMENTO E ORGANIZAÇÃO: indicativos pós-Bolonha de uma sociedade em construção. Revista Observatório, v. 3, n. 6, p. 338-353, 1 out. 2017.

OLIVEIRA, E. M. RESPONSABILIDADE SOCIAL EMPRESARIAL, EMPREENDEDORISMO SOCIAL E ECONOMIA SOLIDÁRIA: similitudes, ambivalências e possíveis conexões. Revista Observatório, v. 5, n. 5, 20 jul. 2019.

PAZ, E. H. BEST-SELLERS DA DITADURA: os livros mais vendidos sob o Al-5. Revista Observatório, v. 5, n. 5, 1 ago. 2019..

RIBEIRO, M. S.; CARVALHO, R. L. DE; OLIVEIRA, A. H. M.; BOTELHO, G. M.; PESSOA, W. M. Smart Cities DESAFIOS GERADOS PELO CRESCIMENTO POPULACIONAL URBANO NO CONTEXTO DAS CIDADES INTELIGENTES. Revista Observatório, v. 5, n. 5, 1 ago. 2019..

RODRÍGUEZ, V. M. A. O MUSEU FORA E DENTRO DA AULA DE PRIMÁRIA. Revista Observatório, v. 5, n. 5, 1 ago. 2019..

SANTANA, C. L.; COUTO, E. S. ENTRE TWEETS: audiências, conexões e indexações de professores no twitter. Revista Observatório, v. 5, n. 5, 14 jan. 2020.

SANTOS TIZZO, A. L.; CARVALHO, D. F. EXPERIÊNCIAS EM MUSEUS POSSUEM A CAPACIDADE DE EVOCAR LEMBRANÇAS EM UM PÚBLICO DE TERCEIRA IDADE? . Revista Observatório, v. 5, n. 5, 1 ago. 2019..

SANTOS, E. M.; LASTÓRIA, L. A. C. N. TECNOLOGIAS DIGITAIS E EDUCAÇÃO: impactos e desafios para uma nova configuração de subjetividade. Revista Observatório, v. 5, n. 5, 1 ago. 2019..

SANTOYO, A.; NUNES, S. G. DA C.; RESENDE JUNIOR, H. N. A UTILIZAÇÃO DAS MÍDIAS SOCIAIS NO PROCESSO DE PLANEJAMENTO DE VIAGENS. Revista Observatório, v. 5, n. 5, 1 ago. 2019..

SOUSA, K. A.; LUCAS, M. R.; SOUZA, D. O. DE S.; COSTA, B. B. A PRODUÇÃO DA BANANA E SEUS IMPACTOS SOCIOECONÔMICOS NO DESENVOLVIMENTO DA MICRORREGIÃO DE ARAGUAÍNA-TO. Revista Observatório, v. 5, n. 5, 1 ago. 2019. SOUZA, D. O. DE; SOUZA, M. T. S. DE; DANTAS, E. L. B. IMPASSES TECNOLÓGICOS PARA GESTÃO DO CICLO BIOLÓGICO DA ECONOMIA CIRCULAR NA INDÚSTRIA DE PROCESSAMENTO DE CARNE BOVINA. Revista Observatório, v. 5, n. 5, 1 ago. 2019.

SOUZA, F. DA C.; MORAES, N. R. DE. ESTADO DE BEM-ESTAR SOCIAL: UMA REVISÃO DE LITERATURA. Revista Observatório, v. 5, n. 5, 1 ago. $2019 .$.

SOUZA, W. DA S.; HUERTAS, M. K. Z.; MORAIS, F. R. DE; BATISTA, J. M. AJUDE-ME POR FAVOR! O efeito da cocriação na persuasão de consumidores. Revista Observatório, v. 5, n. 5, 1 ago. 2019.. 


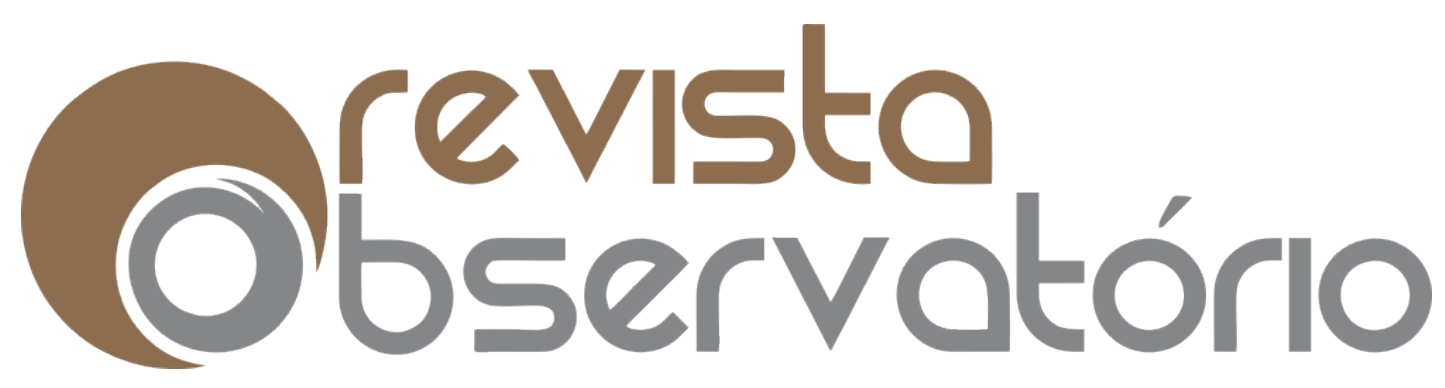

ISSN n² 2447-4266

Vol. 5, n. 5, Agosto. 2019

DOI: http://dx.doi.org/10.20873/uft.2447-4266.2019v5n5p26

SPINELLI, E. M.; SANTOS, J. DE A. JORNALISMO NA ERA DA PÓS-VERDADE: factchecking como ferramenta de combate às fake news. Revista Observatório, v. 4, n. 3, p. 759-782, 29 abr. 2018.

TEIXEIRA, I.; SILVA, P. C. DA; SOUSA, S. L. DE; SILVA, V. C. DA. NOMOFOBIA: OS impactos psíquicos do uso abusivo das tecnologias digitais em jovens universitários. Revista Observatório, v. 5, n. 5, 1 ago. 2019.

THEODORO, L. S. A.; PORTO JUNIOR, F. G. R. OS OLHARES DA COMUNICAÇÃO ORGANIZACIONAL NO BRASIL PARA O ENSINO SOB O PARADIGMA DA COMPLEXIDADE. Revista Observatório, v. 5, n. 5, p. 999-1021, 1 ago. 2019.

VIANA, H. J. A.; MUSSE, C. F.; MAGNOLO, T. S. SÉRIES TELEVISIVAS BRASILEIRAS: a narrativa e a ressignificação da história recente nacional em "OS DIAS ERAM ASSIM" . Revista Observatório, v. 5, n. 5, 1 ago. 2019..

VIANA, J.; COSTA, F. A.; PERALTA, H. APRENDIZAGENS PESSOAIS EM CONTEXTOS INFORMAIS: oportunidades criadas pela Internet. Revista Observatório, v. 3, n. 4, p. 190-231, 1 jul. 2017.

VICENTE, K. B.; SOUSA, F. D'ABADIA DE. VIDAS FOTOGRAFICAMENTE EDITADAS. Revista Observatório, v. 5, n. 5, 1 ago. 2019.

WALCHHUTTER, S.; KALIL HANNA, E.; SOUZA, W. DA S. INOVAÇÃO VERDE: Produtos e processos como fator de vantagem competitiva. Revista Observatório, v. 5, n. 5, 1 ago. 2019..

ZACARIOTTI, M. E. C. O "EXTREMO" PARA PENSAR A CULTURA DAS JUVENTUDES CONTEMPORÂNEAS. Revista Observatório, v. 5, n. 5, 1 ago. 2019. 